\title{
Programa de Ecoturismo e Educação Ambiental do Projeto TAMAR - Fernando de Noronha: uma análise de 2013 a 2016
}

\section{Ecotourism and Environmental Education Program of the TAMAR Project - Fernando de Noronha (PE, Brazil): an analysis from 2013 to 2016}

\section{Laissa Paloma Queiroz de Lima, Lourival Dutra Neto, Luciana Araújo de Holanda}

\begin{abstract}
RESUMO: O arquipélago de Fernando de Noronha (PE), formado por ilhas, ilhotas e rochas de origem vulcânica no oceano atlântico sul, tornou um destino turístico de destaque no segmento de Ecoturismo em nível nacional e internacional. Em meio ao processo de turistificação da ilha, o Projeto TAMAR tem desenvolvido, desde 1984, ações de sensibilização ambiental. O Programa de Ecoturismo e Educação Ambiental, por exemplo, traz à tona a problemática de proteção ambiental e busca sensibilizar seus participantes sobre a importância da conservação da biodiversidade, tendo como agente principal as tartarugas-marinhas. O presente artigo se propõe a mensurar e analisar o fluxo de participantes no período de 2013 a 2016, bem como as atividades realizadas no âmbito deste Programa. Para tanto, adotou-se como procedimentos metodológicos a pesquisa bibliográfica, documental e de campo - caracterizada como pesquisa quantitativa de natureza descritiva. Os resultados apontam que, no quadriênio analisado, todas as atividades tiveram incremento de público e quase 160.000 pessoas participaram do Programa, no entanto as atividades que tiveram aumento da média mensal de participantes foram aquelas onde o público tem maior interação com o meio ambiente e as tartarugas marinhas.
\end{abstract}

PALAVRAS-CHAVE: Educação Ambiental; Projeto TAMAR; Fluxo de Participantes.

\section{ABSTRACT}

The archipelago of Fernando de Noronha (PE), formed by islands, islets and rocks of volcanic origin in the South Atlantic Ocean, has become a prominent tourist destination in the segment of Ecotourism at national and international level. In the midst of the touristification process of the island, the TAMAR Project has developed environmental awareness actions since 1984. The Ecotourism and Environmental Education Program, for example, brings up environmental protection issues and intends to sensitize people on the importance of biodiversity conservation, with sea turtles as its main agent. The present article proposes to measure and analyze the flow of participants during the period of 2013 to 2016, as well as the activities carried out under the Program. To that end, methodological procedures were adopted for bibliographic, documentary and field research - characterized as a descriptive research with a quantitative approach. The results show that, in the four-year analyzed period, all activities had a rise in the in the number of participants and almost 160,000 people have participated in the Program. However, the activities that have increased its monthly average were those where the participants have the chance to interact with the environment and sea turtles.

KEYWORDS: Environmental Education; TAMAR Project; Flow of Participants. 


\section{Introdução}

A Educação Ambiental é um tema de envolvimento e interesse em nível global. A Organização das Nações Unidas (ONU) tem promovido importantes encontros e reunido os principais líderes mundiais a fim de discutir questões referentes ao meio ambiente, preservação da natureza e desenvolvimento sustentável. Desde a primeira Conferência Mundial sobre Homem e o Meio Ambiente, realizada em Estocolmo em 1972, a Educação Ambiental tem sido utilizada como instrumento para a viabilização da sustentabilidade em nossa sociedade, pensando o meio ambiente não apenas como um sinônimo de natureza, mas "uma base de interações entre o meio físico-biológico com as sociedades e a cultura produzida pelos seus membros", como afirma Sorrentino et al. (2005, p.289).

No Brasil, a Educação Ambiental ganhou visibilidade com a realização da Conferência Rio-92, também conhecida como ECO 92, realizada no Rio de Janeiro. Em termos legais, o primeiro dispositivo que regulamenta a Educação Ambiental no país é a lei $n^{\circ}$ 9.795/99 que instituiu a Política Nacional de Educação Ambiental (PNEA). Nela, a Educação Ambiental é concebida como componente essencial e permanente da educação no país, em todas as modalidades e níveis de ensino, formal ou não formal, e a responsabilidade da execução de seus princípios básicos, objetivos e estratégias é de origem coletiva.

Essa concepção da Educação Ambiental foi adotada por várias organizações que executam, inclusive, atividades interligadas ao turismo, em especial nos locais onde a atividade turística se desenvolve em ambientes naturais. Esse é o caso do TAMAR, projeto conservacionista criado em 1980 que passou a designar o Programa Nacional de Conservação de Tartarugas Marinhas e que hoje é a soma de esforços entre a Fundação Pró-TAMAR criada para executar o trabalho de conservação - e o Instituto Chico Mendes da Biodiversidade (ICMBio), órgão do Ministério do Meio Ambiente.

A missão principal do TAMAR é o compromisso com a pesquisa, conservação e manejo das cinco espécies de tartarugas marinhas que ocorrem no Brasil - todas em perigo de extinção. São cerca de $1.100 \mathrm{~km}$ de praias protegidas em 25 localidades divididas ente áreas de alimentação, desova, crescimento e descanso desses animais. O Projeto está presente em nove estados brasileiros e nas regiões litorâneas com potencial turístico, onde mantém Centros de Visitantes que funcionam como núcleos de sensibilização e Educação Ambiental, além de oferecer lazer, entretenimento e serviços.

O Projeto TAMAR instalou sua base no arquipélago de Fernando de Noronha (PE) no ano de 1984, e desde então, tem se preocupado em colocar a sensibilização ambiental em sua pauta, buscando conscientizar os visitantes e moradores por meio de um programa de sensibilização. O Programa de Ecoturismo e Educação Ambiental do Projeto TAMAR em Fernando de Noronha "é uma iniciativa que traz à tona a problemática de proteção ambiental e busca sensibilizar seus participantes sobre a importância da conservação da biodiversidade, tendo como agente principal as tartarugasmarinhas" (PINHEIRO; RODRIGUES; ROBLES, 2013, p.1028). 
O Programa de Ecoturismo e Educação Ambiental deu os primeiros passos com a criação do Ciclo de Palestras, há mais de 20 anos e, desde então, demonstra indiscutível relevância em relação à disseminação da Educação Ambiental, principalmente no contexto da llha de Fernando. Milhares de turistas já tiveram a oportunidade de acompanhar as atividades do TAMAR. Em se tratando de moradores da llha, pode-se dizer que gerações vêm acompanhando o trabalho do Projeto.

Nesse contexto, o presente artigo se propõe, por meio de análise quantitativa, a conhecer o fluxo de participantes das atividades que compõem - Programa de Ecoturismo e Educação Ambiental do Projeto TAMAR em Fernando de Noronha (PE), a fim de mensurar o número de atividades realizadas, bem como o número total e a média mensal de participantes em cada atividade no período de 2013 a 2016. Ademais, serão incluídos aspectos qualitativos à análise de modo, a investigar as algumas questões em relação à repercussão das atividades nos participantes, em termos de sensibilização ambiental.

\section{Educação Ambiental e Ecoturismo}

Conhecer a Educação Ambiental e seu papel, bem como torná-la uma prática, faz parte de um amplo processo de educação, que inclui as várias formas pelas quais a sociedade deve construir valores, competências, habilidades e ações ou atitudes voltadas para a preservação e conservação do meio ambiente, o qual consiste em "um bem de uso comum do povo, essencial à sadia qualidade de vida e sua sustentabilidade" (PNEA, 1999, p.1).

A Educação Ambiental é descrita, no artigo $2^{\circ}$ do documento estabelecido pela lei $N^{0} 9.795 / 1999$, como "um componente essencial $e$ permanente da educação nacional, devendo estar presente, de forma articulada, em todos os níveis e modalidades do processo educativo, em caráter formal e não formal' (BRASIL, 2005, p.30).

No artigo 28 do Plano Nacional de Educação (PNE), aprovado pela Lei № 13.005/2014, é reafirmado o compromisso em tratar a Educação Ambiental como tema transversal, devendo essa ser integrada, contínua e permanente de acordo com a Política Nacional de Educação Ambiental (PNEA).

Para Coutinho, Silva e Silva (2014), a Educação Ambiental é um instrumento que conduz e incentiva mudanças de valores nos seres humanos em relação à natureza, colaborando, significativamente, para que a espécie humana se perceba como integrante de um sistema ecológico. De acordo com Philippi e Pelicioni (2005, p.6), “a Educação Ambiental prepara para o exercício da cidadania por meio da participação ativa individual e coletiva, considerando os processos socioeconômicos, políticos e culturais que a influenciam".

Dessa forma, julga-se relevante citar que, além de entender-se parte de um todo, o indivíduo deve atentar-se para o fato de que interfere, direta e indiretamente, no meio em que habita, fazendo-se necessário com que existam direitos, mas também deveres em relação ao ambiente. 
Atualmente, o planejamento de várias atividades econômicas e sociais é baseado em pilares de conscientização, buscando minimizar os impactos negativos que as mesmas podem trazer. Tendo em vista que o futuro do meio ambiente depende das atitudes que moldam a relação da sociedade com 0 mesmo, a Educação Ambiental exerce papel preponderante por ser capaz de promover mudanças sociais, econômicas e até nos modelos de desenvolvimento.

Práticas voltadas para turismo, por exemplo, devem atentar para 0 comprometimento com a Educação Ambiental e busca pela sustentabilidade, uma vez que turismo e meio ambiente apresentam uma relação de interdependência. Alves e Machado (2014) afirmam que, pela natureza de sua atividade e devido à sua dependência e necessidade de manutenção de boas condições ambientais, o turismo precisa guiar esforços para a consolidação de práticas ambientais sustentáveis.

Uma vez que depende da natureza e seus recursos (atrativos naturais) para ser viabilizado, o turismo tem papel fundamental em se tratando de conscientização para a conservação do ambiente. Unir turismo e Educação Ambiental, dessa forma, torna-se imprescindível.

A Educação Ambiental deverá ser desenvolvida por meio de programas não formais chamando o "cidadão - turista" a uma participação consciente na proteção do meio ambiente não apenas durante suas férias, mas também no cotidiano, no local de residência permanente (RUSCHMANN, 2001, p.5)

A conexão entre Educação Ambiental e turismo fica mais evidente por meio do ecoturismo, enquanto prática alternativa do turismo. Daly (2005) afirma que o turismo, ao assumir os princípios do ecoturismo, tem papel destacado na questão de conservação da natureza. Disseminar o conhecimento ambiental por meio de ecoturismo possibilita a conscientização da sociedade sobre a biodiversidade. Sendo assim, o ecoturismo, proporciona as oportunidades como incentivo à interpretação e à Educação Ambiental (ROCKTAESCHEL, 2006).

Bueno e Pires (2006, p.16), acerca do ecoturismo, afirmam que:

o ecoturismo deve ser compreendido não somente como um segmento turístico, mas como uma atividade que se afina aos ideais ambientalistas e promove experiências privilegiadas de educação, que estimulam a elucidação de valores e incentivam atitudes em prol da conservação da natureza e da consolidação de um novo comportamento social, o qual pode ser alcançado pela adoção das modalidades de Educação Ambiental.

O ecoturismo tem atraído cada vez mais pessoas que se interessam pelo meio ambiente. $O$ estudo publicado na Tourism International Ecotourism 
Society (TIES, 2015) estima que as Áreas de Proteção Ambiental (APA) no mundo recebem juntas em torno de 8 bilhões de visitantes por ano.

De acordo com o Global Travel and Tourism Report 2015, relatório do World Economic Forum, o Brasil é considerado o país com maior potencial turístico em recursos naturais no mundo. Essa riqueza natural pressupõe o turismo de natureza como um dos vetores de crescimento da atividade turística no país.

No Brasil, o segmento de natureza, ecoturismo e aventura é o segundo no ranking de motivações das viagens, sendo colocado de lado apenas pelo turismo de sol e praia, como mostrado na Tabela 1.

Tabela 1: Perfil da demanda turística internacional - Síntese Brasil 2011 - 2015.

Table 1: International tourist demand profile - Brazil Synthesis $2011-2015$.

\begin{tabular}{c|c|c|c|c|c}
\hline \multicolumn{5}{c|}{ Motivação da viagem } & \multicolumn{5}{c}{$\%$} \\
\hline Ano & 2011 & 2012 & 2013 & 2014 & 2015 \\
\hline Sol e praia & 62,1 & 64,2 & 65,9 & 49,2 & 69,4 \\
\hline Cultura & 24,6 & 21,3 & 19,0 & 12,8 & 15,7 \\
\hline Esportes & 9,4 & 10,6 & 11,4 & 10,3 & 12,1 \\
\hline Diversão noturna & 1,6 & 1,9 & 1,8 & 1,7 & 1,5 \\
\hline Outros & 0,9 & 0,9 & 0,9 & 0,4 & 0,6 \\
\hline
\end{tabular}

Fonte: Ministério do Turismo e Fundação Instituto de Pesquisas Econômicas (2016).

Source: Ministry of Tourism and Economic Research Foundation Institute (2016).

Em paralelo ao crescimento do interesse pelo meio ambiente e da demanda turística ao longo dos anos, emerge a necessidade da Educação Ambiental por meio do ecoturismo, possibilitando a sensibilização em relação ao meio ambiente (ROCKTAESCHEL, 2006).

Embora o Brasil seja detentor de recursos naturais ímpares que o tornam o país com maior potencial turístico no mundo, o desenvolvimento sustentável do turismo e viagens é avaliado como regular, segundo o World Economic Forum (2015), sendo assim imprescindível a tomada de decisões em prol da conservação do nosso patrimônio natural e ambiental.

\section{Metodologia}

O presente trabalho caracteriza-se como uma pesquisa aplicada, na qual se tem como propósito fundamental o interesse pela utilização nas consequências práticas dos conhecimentos (GIL, 2008). Em relação à abordagem, classifica-se como pesquisa quantitativa pela objetividade e mensuração dos dados por meio de técnicas de análise estatística não probabilística (BRYMAN, 1995 apud RABECHINNI JUNIOR, 2005, p.27), onde os dados foram analisados com o auxílio do Microsoft Excel. Quanto ao objetivo, trata-se de uma pesquisa descritiva, posto que busca descrever as características da população ou fenômeno estudado (GIL, 2002).

Assim sendo, a pesquisa de campo ocorreu em paralelo às pesquisas bibliográfica e documental. A pesquisa bibliográfica se deu por meio de consultas em livros e artigos científicos que relacionam os temas Educação Ambiental e Ecoturismo. Já a pesquisa documental foi realizada com 
documentos de primeira e segunda mão, referentes aos anos de 2013 a 2016, cedidos pela coordenação do Centro de Visitantes do Projeto TAMAR/FEN, a saber: a) fotos e dados ainda não tratados das atividades do Programa de Ecoturismo e Educação Ambiental; b) Relatórios semanais e mensais e c) dados do Sistema de Informações para Geração de Relatórios (SIGRE), conforme detalhado no Quadro 1.

Quadro 1: Fontes de dados utilizadas pelos autores na pesquisa documental.

Table 1: Data sources used by the authors for the documentary research.

\begin{tabular}{|l|l|}
\hline \multicolumn{1}{|c|}{ Documento } & \multicolumn{1}{c|}{ Descrição } \\
\hline Relatórios Semanais & $\begin{array}{l}\text { Controle diário e semanal das atividades executadas nas } \\
\text { bases do Projeto TAMAR. Nesse caso, no Centro de } \\
\text { Visitantes de Fernando de Noronha. Os dados são } \\
\text { apresentados em Planilhas do Microsoft Excel/Open Office. }\end{array}$ \\
\hline Relatórios Mensais & $\begin{array}{l}\text { Controle mensal das atividades que estão sendo executa- } \\
\text { das nas bases do Projeto TAMAR. Nesse caso, no Centro } \\
\text { de Visitantes de Fernando de Noronha. Os dados são apre- } \\
\text { sentados em Slides do Microsoft PowerPoint/Open Office. }\end{array}$ \\
\hline $\begin{array}{l}\text { Sistema de Informações para } \\
\text { Geração de Relatórios (SIGRE) }\end{array}$ & $\begin{array}{l}\text { Software Online utilizado para registrar todos os dados aos } \\
\text { quais se referiu anteriormente. }\end{array}$ \\
\hline
\end{tabular}

Fonte: Elaborado pela autora.

Source: Created by the author.

$\mathrm{Na}$ pesquisa de campo, realizada in loco, utilizou-se a técnica de observação não estruturada no intuito de extrair informações complementares à análise, o que ocorreu de maneira natural e espontânea. De acordo com Gil (2002), a observação se constitui como um elemento fundamental para a pesquisa, tendo em vista que ela possibilita delinear as fases da mesma, coletar dados, complementar procedimentos, entre outros. A observação participante foi utilizada enquanto método de investigação, considerando que coube a uma das autoras desse estudo acompanhar o Programa de Ecoturismo e Educação Ambiental e auxiliar os biólogos do TAMAR no planejamento e execução de suas atividades. Quanto à utilização de ambas as abordagens quanti e qualitativas, estas "podem ser complementares e adequadas para minimizar a subjetividade e aproximar o pesquisador do objeto de estudo, respondendo às principais críticas das abordagens, proporcionando maior confiabilidade aos dados" (TERENCE; ESCRIVÃO FILHO, 2006, p.5).

Nessa etapa, realizou-se uma imersão no trabalho desenvolvido pelo TAMAR por meio do acompanhamento das seis atividades que compõem o Programa de Ecoturismo e Educação Ambiental: Captura Científica, Soltura de Filhotes, Ciclo de Palestras, Ilhatour, Visita Guiada no Museu Aberto da Tartaruga Marinha e Tartarugada. As atividades elegidas para análise de dados têm uma característica em comum, que é o fato de ocorrerem com periodicidade. Dessa maneira, as duas últimas citadas, respectivamente, não serão incluídas no presente artigo ${ }^{1}$.

Os dados obtidos em cada atividade do Programa de Ecoturismo e Educação Ambiental do Projeto TAMAR (documentos, contagem de participantes, fotografias, quantidade de atividades realizadas, etc.) são normalmente inseridos pelos pesquisadores nos relatórios semanais e mensais já mencionados, bem como no SIGRE. A contagem do número total 
de participantes nas atividades do Programa de Ecoturismo e Educação Ambiental é tradicionalmente realizada com o auxílio de um contador manual e câmera fotográfica - métodos também utilizados para a obtenção de dados desse estudo.

As informações coletadas nas pesquisas de campo e documental foram analisadas por meio de estatística descritiva não probabilística. Visando mensurar o número de atividades desempenhadas pelos pesquisadores, bem como o número de participantes em cada uma, realizou-se a soma de cada atividade desempenhada ao longo dos anos (gráficos 1 e 2); utilizou-se a média aritmética simples no intuito de obter valores que descrevam a média do número de participantes ao longo do quadriênio (gráfico 3); já o número total de público (gráfico 4) foi obtido por meio da soma de participantes das seguintes atividades: Ilhatour, Ciclo de Palestras, Captura Científica e Soltura de Filhotes. Reitera-se que os resultados apresentados nos gráficos a seguir referem-se ao período de 2013 a 2016.

\section{Apresentação e Análise dos Dados}

No arquipélago de Fernando de Noronha (PE) está presente uma das bases onde o Projeto TAMAR atua com a pesquisa e conservação de tartarugas marinhas. No período de janeiro de 2013 a dezembro de 2016, as atividades que constituem o Programa de Ecoturismo e Educação Ambiental do Projeto contaram com a participação de um total de 159.919 pessoas. Diante desse número, cabe colocar em pauta a relevância do Programa de Ecoturismo e Educação Ambiental do Projeto Tamar no que concerne à sensibilização ambiental, voltando-se para o dever da Educação Ambiental na busca pela construção de hábitos e atitudes sustentáveis, não apenas limitando-se à difusão do conhecimento (BARBOSA; RADICCHI, 2008), em outras palavras, trata-se de sensibilizar e conscientizar. Sobre tais iniciativas, Ferreira (2015, p. 174), acrescenta: "são ações subjetivas e, por isso, difíceis de mensurar". Nesse contexto, ao decorrer da análise quantitativa do presente estudo, serão inseridos apontamentos com vistas a ampliar o panorama que os dados analisados evidenciam e assim, brevemente discorrer sobre quais são as repercussões das atividades do Programa de Ecoturismo e Educação Ambiental nos participantes, em termos de conscientização/sensibilização ambiental.

O TAMAR desenvolve atividades de Educação Ambiental em Fernando de Noronha desde o ano de 1996, tendo sido primeiramente criado o Ciclo de Palestras Ambientais que acontece todos os dias da semana no auditório do Centro de Visitantes, há 21 anos. O Ciclo de Palestras ambientais do TAMAR é um marco no que concerne à Educação Ambiental para os visitantes, turistas e moradores da llha, com ampla abordagem de temas relacionados à flora e à fauna local (tartarugas marinhas, golfinhos, tubarões), bem como outros aspectos do arquipélago. "As palestras ambientais do Projeto se caracterizam como uma forma de interpretação ambiental, e podem sensibilizar o público sobre a importância da conservação" (MOREIRA; ROBLES; BELINI, 2009 apud GERHARDT et al., 2015, p.1). 
O Ilhatour, mais uma atividade do Programa de Ecoturismo e Educação Ambiental, foi criado em agosto de 2014 e é realizado em parceria com a empresa Atalaia Turismo. O Centro de Visitantes recebe, diariamente, grupos de turistas, onde geralmente o estagiário de turismo, com auxílio do Coordenador, orienta sobre as atividades desenvolvidas e oferecidas pelo TAMAR em Fernando de Noronha, além de explicar sobre alguns objetos expostos no Museu Aberto da Tartaruga Marinha.

A Captura Científica ocorre periodicamente: duas vezes por semana pesquisadores do TAMAR mergulham com a intenção de capturar tartarugas a fim de coletar dados, colocar anilhas de identificação, realizar a biometria da carapaça, entre outros. A Soltura de Filhotes de tartarugas marinhas, importante ferramenta de sensibilização e Educação Ambiental, acontece somente dentro do período reprodutivo das Tartarugas Verdes no Arquipélago - que ocorre de dezembro a junho. Após monitorar e acompanhar os ninhos, os biólogos selecionam aqueles em condições ideais para realizar uma "abertura de ninho" pública. Momentos antes de ver as tartarugas nascendo e indo para o mar, os participantes aprendem sobre os cuidados necessários para evitar impactos sobre os filhotes, além de receberem informações o ciclo de vida dos mesmos.

O Gráfico 1 ilustra a quantidade de atividades realizadas, anualmente, dentro do Programa de Ecoturismo e Educação Ambiental do Projeto TAMAR - Fernando de Noronha que foram analisadas no presente artigo. Observa-se que o Ciclo de Palestras é a atividade que acontece mais vezes durante o ano, juntamente com o Ilhatour, posto que são realizadas de maneira diária e ininterrupta. A soltura de filhotes, por sua vez, é a atividade menos frequente, pois depende do período reprodutivo das tartarugas marinha no Arquipélago que dura, em média, 5 meses do ano.

Gráfico 1: Comparativo do número de atividades realizadas por ano.

Chart 1: Comparison of the number of activities performed per year.

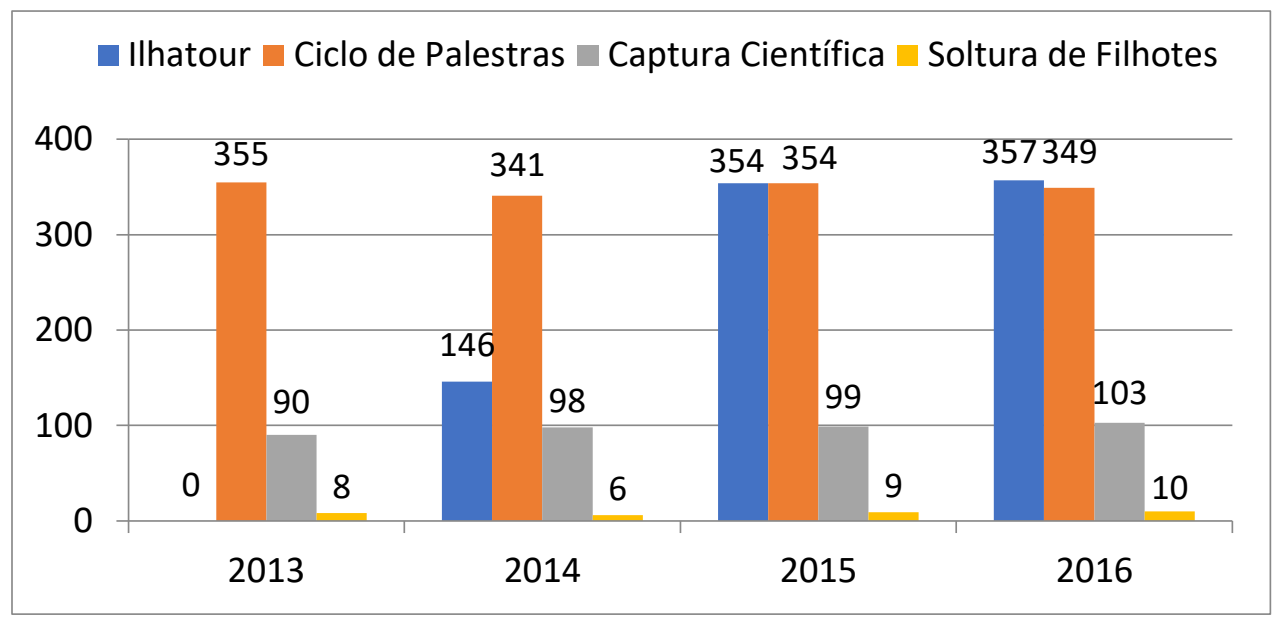

Fonte: Elaborado pela autora com base em relatórios semanais e mensais $2013-2016$.

Source: Created by the author based on weekly and monthly reports $2013-2016$.

Os resultados analisados expõem que o Ciclo de Palestras e o Ilhatour são, além das mais realizadas, as atividades que têm recebido o maior 
público no período de tempo a que se refere esta pesquisa. Estas atividades não possuem grande variação de programação. As informações repassadas no Ilhatour são pontuais e sucintas. O Ciclo de Palestras tem planejamento semanal, no entanto suas palestras pouco variam. Durante a coleta de dados percebeu-se que (geralmente) nas segundas-feiras, por exemplo, existe uma apresentação sobre o PARNAMAR de Fernando de Noronha; nas quartas, a palestra é sobre os Golfinhos Rotadores; nas sextas, Tubarões - nas semanas seguintes a programação se repete. Notou-se que existe 0 questionamento dos participantes sobre a pouca variação dessas atividades e essa recorrência possivelmente reflete na diminuição do público nas atividades (Gráficos 2 e 3).

De acordo com Ferreira (2008, p. 166) "a função de programas de mobilização e sensibilização é contribuir para a formação de cidadãos críticos e participativos em relação ao meio", nesse sentido, no que concerne à sensibilização ambiental, considerando o contexto do Programa de Ecoturismo e Educação Ambiental do Projeto TAMAR, acredita-se que tanto o Ilhatour quanto o Ciclo de Palestras necessitam de uma adaptação, visando que se adequem à transformação proposta pelo autor supracitado. É indispensável que a programação dessas atividades seja moldada sob a perspectiva de que para a sensibilização ambiental acontecer, é necessário que abranja diversas áreas do conhecimento, buscando construir 0 conhecimento de uma forma transversal.

A seguir, podem ser conferidos os números que determinam a quantidade de pessoas que participaram das atividades do Programa de Ecoturismo e Educação Ambiental ao longo dos anos (Gráfico 2).

Gráfico 2: Número total de participantes por ano.

Chart 2: Total number of participants per year.

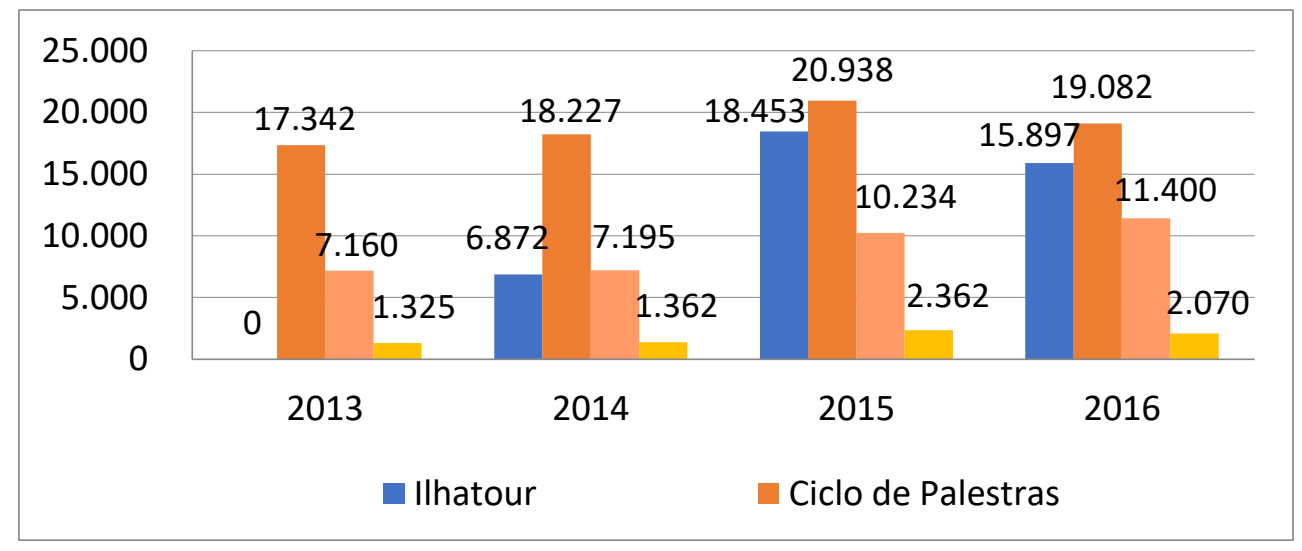

Fonte: Elaborado pela autora com base em relatórios semanais e mensais $2013-2016$.

Source: Created by the author based on weekly and monthly reports $2013-2016$.

Sobre o número total de participantes por ano, os dados demonstram que o Programa de Ecoturismo e Educação Ambiental obteve aumento de público em quase todas as atividades ao longo do tempo. Esse é um fator positivo que evidencia a aceitação das pessoas em relação às ações do 
Projeto TAMAR. Além disso, destaca-se o fato de que cada vez mais indivíduos, majoritariamente turistas, estão sendo inseridos nas ações de sensibilização ambiental em Fernando de Noronha - é importante ressaltar a ausência de instrumento que identifique a composição dos participantes nas atividades. Em relação à média mensal de participantes ao longo dos anos em cada atividade realizada pelo Projeto TAMAR, apenas a Captura Científica e a Soltura de Filhotes registraram aumento, enquanto o Ciclo de Palestras e - Ilhatour apresentaram pequeno declínio a partir de 2015 (Gráfico 3). O aumento de público nas respectivas atividades evidencia que as pessoas têm demonstrado preferência por ações onde existe maior interação do participante - seja com o pesquisador, com o meio ambiente ou com as tartarugas marinhas.

Gráfico 1: Média mensal de participantes por ano.

Chart 3: Monthly average of participants per year.

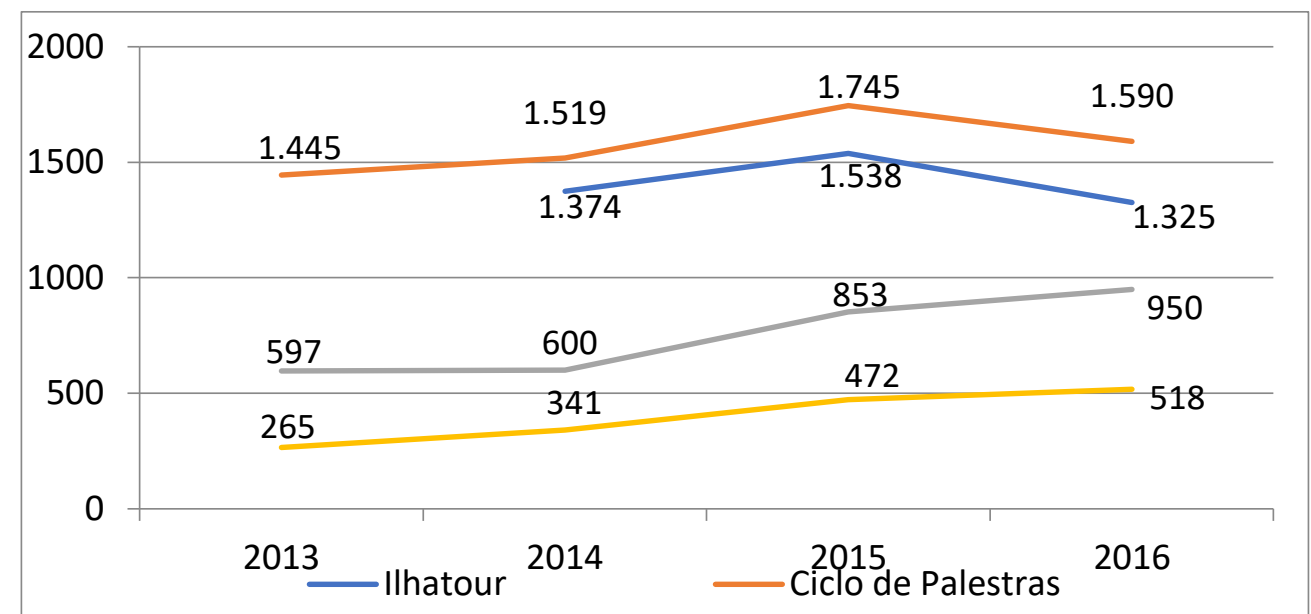

Fonte: Elaborado pela autora com base em relatórios semanais e mensais $2013-2016$.

Source: Created by the author based on weekly and monthly reports $2013-2016$.

Tanto a Captura Científica quanto a Soltura de Filhotes de tartarugas marinhas ocorrem nas praias do Arquipélago e têm cunho mais interativo: é geralmente onde o público tem grande chance de ver de perto tartarugas juvenis ou filhotes nascendo e a consequência disso é o maior contato com o animal em seu meio. Foi possível perceber que tanto na Captura Científica quanto na Soltura de Filhotes, os pesquisadores incentivam a participação do público, e isso tem um retorno positivo dos participantes. Com base na observação realizada na pesquisa de campo, chegou-se à conclusão de que essas são as atividades que despertam maior sensibilização do público em relação à preservação do meio ambiente, ciclo de vida e conservação das tartarugas marinhas, etc. Chama-se atenção para o fato de serem realizadas in loco (nas praias do arquipélago), além de carregarem aspectos únicos, como a experiência acompanhar as tartarugas marinhas em seu habitat.

O gráfico a seguir apresenta a distribuição percentual do público nas atividades realizadas pelo TAMAR. Apesar de não ter apresentado crescimento expressivo nos últimos 4 anos, o Ciclo de Palestras ainda é a atividade que recebe maior número de participantes, sendo seu público 
equivalente a quase $50 \%$ do total de pessoas que acompanharam as atividades do Projeto TAMAR em Noronha no período de 2013 a 2016.

Gráfico 2: Distribuição do público por atividade de 2013 a 2016.

Chart 4: Distribution of the public per activity from 2013 to 2016.

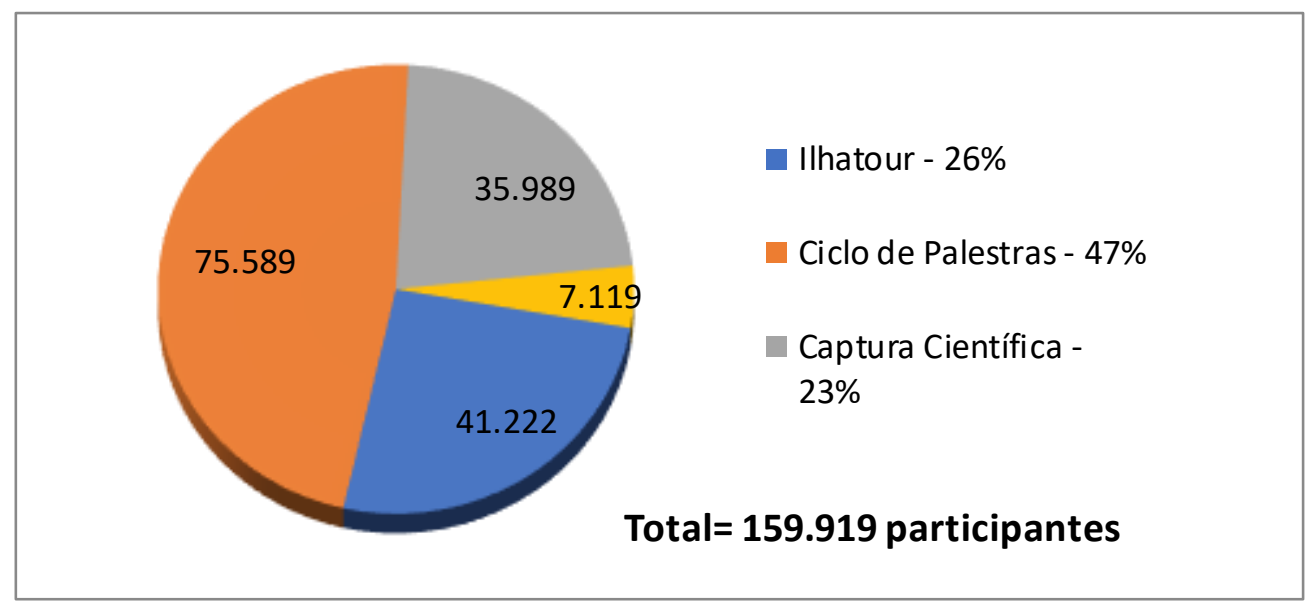

Fonte: Elaborado pela autora com base em relatórios semanais e mensais 2013 - 2016.

Source: Created by the author based on weekly and monthly reports $2013-2016$.

Em geral, verificou-se que no quadriênio analisado, todas as atividades tiveram incremento de público e aproximadamente $160.000^{2}$ pessoas participaram do Programa de Ecoturismo e Educação Ambiental do Projeto TAMAR em Fernando de Noronha. O Ciclo de Palestras é a atividade mais realizada e a que apresenta maior número total de participantes, seguida do llhatour. As atividades que tiveram aumento da média mensal de participantes, em contrapartida, foram aquelas onde o público tem maior contato com as tartarugas marinhas, ou seja, a Captura Científica e a Soltura de Filhotes.

Apesar da expressividade dos dados e da longa existência do Programa de Ecoturismo e Educação Ambiental, observou-se que o Projeto TAMAR não possui ferramentas eficientes que possibilitem identificar informações a fim de direcionar as ações sensibilização. Segundo Gonzalez, Tozoni-Reis e Diniz (2007), para colaborar na construção de uma nova concepção ambiental e de um novo cidadão, os princípios da Educação Ambiental devem estar nos alicerces das ações ambientais educativas. Assim sendo, torna-se imprescindível que os educadores/ pesquisadores do Projeto tomem consciência da complexidade de seu trabalho e da importância de desenvolvê-lo da melhor maneira.

\section{Considerações Finais}

A Educação Ambiental tem papel fundamental na transformação dos indivíduos, sendo uma ferramenta imprescindível na promoção de novas atitudes em relação à proteção do meio ambiente. O Programa de Ecoturismo e Educação Ambiental do TAMAR em Fernando de Noronha tem uma relação direta com os visitantes da llha e a realização do presente estudo possibilitou deparar-se com a relevância do Projeto, que há vários anos difunde a 
conservação da biodiversidade em busca da sensibilização da comunidade local e dos turistas.

Considerando apenas os quatro últimos anos de seu acontecimento, constatou-se que quase 160.000 pessoas tiveram a oportunidade de acompanhar a mensagem de preservação ambiental difundida pelo TAMAR. Esse é um número expressivo e que apresenta tendência de crescimento ao longo dos anos. Em contrapartida, as ferramentas utilizadas para contabilizar as atividades do Programa de Ecoturismo e Educação Ambiental não possibilitam identificar quantas dessas pessoas são habitantes da llha e quantas são turistas, respectivamente, sendo esse um fator limitante à realização desta pesquisa. Cabe ressaltar que essa é uma questão relevante, tendo em vista que, com base na observação da pesquisa de campo e dinâmica das atividades, o público constitui-se, em maioria, por turistas.

Em decorrência do que foi citado, indica-se os próximos estudos acerca do Programa de Ecoturismo e Educação Ambiental comprometam-se em analisar e sugerir a melhor maneira de caracterizar os participantes nas atividades do TAMAR, mensurando o número de moradores e turistas que participam das atividades. Além desse aspecto, existem outras questões relevantes a serem investigadas, como a contribuição e repercussão do Programa de Ecoturismo e Educação Ambiental na sensibilização dos participantes, bem como a motivação do público que acompanha as atividades do Projeto em Fernando de Noronha. A partir dessas questões torna-se possível, por exemplo, desenvolver esforços por meio de ações que busquem atrair os moradores, no intuito de que participem mais ativamente das atividades.

Por fim, destaca-se a importância da realização dessa pesquisa, uma vez que os resultados obtidos em relação ao fluxo de participantes das atividades que compõem o Programa de Ecoturismo e Educação Ambiental do Projeto TAMAR no período de 2013 a 2016 possibilitam reiterar a significância das ações de sensibilização ambiental que o mesmo desenvolve em Fernando de Noronha. Espera-se que, a partir dessa análise - e com base em suas implicações, sejam realizadas adequações que possam contribuir para o Projeto TAMAR, para o Programa de Ecoturismo e Educação Ambiental e, até mesmo, para a ampliação de ações voltadas para 0 desenvolvimento do ecoturismo em Fernando de Noronha.

\section{Referências}

BUENO, F.P.; PIRES, P.S. Ecoturismo e Educação Ambiental: possibilidades e potencialidades de conservação da natureza. Seminário de Pesquisa em Turismo do Mercosul, 5., 2006, Caxias do Sul. Anais eletrônicos... Caxias do Sul, 2006. Disponível em: $<$ http://www.ucs.br/ucs/tplSemMenus/eventos/seminarios semintur/semin tur 4/arquivos 4 seminario/GT08-5.pdf>. Acesso em 22 de jul. 2017.

COUTINHO, S.F.S.; SILVA, E.S.; SILVA, P.A. Educação Ambiental e sustentabilidade social e ecológica dos lugares turísticos e de lazer. Revista Brasileira de Ecoturismo, São Paulo, v.7, n.2, p.251-268, 2014. 
DALY, H.E. Sustentabilidade em um mundo lotado. Scientific American Brasil, São Paulo, out. 2005. Reportagem. Disponível em: $<$ http://www2.uol.com.br/sciam/reportagens/sustentabilidade em um mundo lot ado.html>. Acesso em: 20 jul. 2017.

FERREIRA, M.V. Avaliação de projetos de Educação Ambiental na lagoa da Pampulha (MG). Revista Brasileira de Educação Ambiental, São Paulo, v.10, n.1, p.164-179, 2015.

FUNDAÇÃO CENTRO BRASILEIRO DE PROTEÇÃO E PESQUISA DAS TARTARUGAS MARINHAS - PRÓ-TAMAR. Relatórios de Atividades. Fernando de Noronha (PE), 2017.

GERHARDT, C.; ROBLES, R.A.; RODRIGUES, C.G.O; SANTOS, A.J.B.; VALE, T.F; MOREIRA, J.C. O ciclo de palestras ambientais do Projeto TAMAR de Fernando de Noronha e a percepção dos visitantes. Anais. Encontro de Pesquisa de Fernando de Noronha, São Pedro e São Paulo e Atol das Rocas, Disponível em: $<$ http://www.tamar.org.br/publicacoes html/publicacoes/2015.html>.Acesso em 14 jul. 2017.

GIL. A.C. Como elaborar projetos de pesquisa. 4. ed. - São Paulo: Atlas, 2002.

GIL. A.C. Métodos e técnicas de pesquisa social. 6. ed. São Paulo: Atlas, 2008.

GONZALEZ, L.T.V; TOZONI-REIS, M.F.C; DINIZ, R.E.S. Educação Ambiental na comunidade: uma proposta de pesquisa-ação. Revista Eletrônica do Mestrado de Educação Ambiental, v.18, p.379-398, jan/jun 2007.

MINISTÉRIO DO MEIO AMBIENTE. MINISTÉRIO DA EDUCAÇÃO. Programa nacional de Educação Ambiental - ProNEA. 3. ed. Brasília: Ministério do Meio Ambiente, 2005.

MINISTÉRIO DO TURISMO. Fundação Instituto de Pesquisas Econômicas. Estudo da Demanda Turística Internacional - 2011-2015. Brasília, julho de 2016.

PHILIPPI JUNIOR, A.; PELICIONI, F.C.M. Educação Ambiental e sustentabilidade. Barueri: Manole, 2005.

PINHEIRO, M.A.P.; RODRIGUES, C.G.O.; ROBLES, R.A. "Tartarugada”: uma iniciativa de sensibilização ambiental no Parque Nacional Marinho de Fernando de Noronha (PE). Revista Brasileira de Ecoturismo, São Paulo, v.6, n.5, nov2013/jan-2014, p.1028-1051.

RABECHINNI JUNIOR, R. Competências e maturidade em gestão de projetos: uma perspectiva estruturada. São Paulo: Annablume, 2005.

ROCKTAESCHEL, B.M.M.M. Terceirização em áreas protegidas: estímulo ao ecoturismo no Brasil. São Paulo: Editora Senac, 2006. RUSCHMANN, D.M. Turismo e planejamento sustentável: A proteção do meio ambiente. Campinas - SP, Papirus, 2001.

SORRENTINO, M; TRAJBER, R; MENDONÇA, P; FERRARO JUNIOR, L. A. Educação Ambiental como política pública. Revista Educação e Pesquisa, São Paulo, v. 31, n. 2, p. p. 285-299, maio/ago. 2005.

TERENCE, A.C.F.; ESCRIVÃO FILHO, E. Abordagem quantitativa, qualitativa e a utilização da pesquisa-ação nos estudos organizacionais. In: Encontro de engenharia de Produção, 26., Anais eletrônicos... Fortaleza, 9-11 out. 2006. 
Disponível

em: <https://www.abepro.org.br/biblioteca/ENEGEP2006 TR540368 8017.pdf >.

Acesso em: 20 jan. 2018.

THE INTERNATIONAL ECOTOURISM SOCIETY. News. Walk on the Wild Side: Estimating the Global Magnitude of Visits to Protected Areas. Disponível em: <http://www.ecotourism.org/news/industry-news>. Acesso em: 12 de jul. 2017.

WORLD ECONOMIC FORUM. Global Travel and Tourism Report 2015. Disponível em: <http://www3.weforum.org/docs/TT15/WEF Global Travel\&Tourism Report 201 5.pdf $>$. Acesso em 12 Jul. 2017.

WORLD TRAVEL AND TOURISM CONCIL. Economic research. Disponível em: <https://www.wttc.org/research/economic-research/>. Acesso em: 10 jul. 2017.

\section{Notas:}

1 "A 'Tartarugada' é uma atividade que consiste no acompanhamento do trabalho de monitoramento noturno dos pesquisadores do TAMAR na tentativa de flagrar alguma tartaruga em atividade de desova" (PINHEIRO; RODRIGUES; ROBLES, 2014, p.1039). A Visita Guiada acontece no Museu Aberto da Tartaruga Marinha com o acompanhamento dos pesquisadores do Tamar. Dados dessas atividades não foram considerados neste trabalho, dado aos fatos de que a primeira não tem sido ofertada ao público desde 2016, só acontecendo para fins de pesquisa e a segunda não possui periodicidade, ocorrendo apenas de acordo com a disponibilidade dos pesquisadores.

2 Chegou-se a esse número a partir da soma total de público ao longo dos anos nas atividades aqui analisadas (Ilhatour, Captura Científica, Ciclo de Palestras e Soltura de Filhotes), no período de 2013 a 2016.

Laissa Paloma Queiroz de Lima: Universidade Federal de Pernambuco, Recife, PE, Brasil.

E-mail: paloma.queirozdelima@gmail.com

Link para o currículo Lattes: http://lattes.cnpq.br/6972114002521385

Lourival Dutra Neto: Projeto TAMAR, Fernando de Noronha, PE, Brasil.

E-mail: lourival.dutra@tamar.org.br

Link para o currículo Lattes: http://lattes.cnpq.br/0611200802891879

Luciana Araújo de Holanda: Universidade Federal de Pernambuco, Recife, PE, Brasil.

E-mail: luciana.holanda@ufpe.br

Link para o currículo Lattes: http://lattes.cnpq.br/3849123632217263

Data de submissão: 18 de outubro de 2017

Data de recebimento de correções: 08 de janeiro de 2018

Data do aceite: 08 de janeiro de 2018

Avaliado anonimamente 